\title{
Multisensory stimulation in stroke rehabilitation
}

\author{
Barbro Birgitta Johansson* \\ Department of Clinical Neuroscience, Wallenberg Neuroscience Center, Lund, Sweden
}

\section{Edited by:}

Hubert R. Dinse, Ruhr-Universität

Bochum, Germany

\section{Reviewed by:}

Martin Lotze, University of

Greifswald, Germany

Tobias Kalisch, Ruhr-Universität

Bochum, Germany

\section{*Correspondence:}

Barbro Birgitta Johansson,

Department of Clinical Neuroscience Wallenberg Neuroscience Center, BMC A13, SE 22184 Lund, Sweden. e-mail: barbro.johansson@med.lu.se
The brain has a large capacity for automatic simultaneous processing and integration of sensory information. Combining information from different sensory modalities facilitates our ability to detect, discriminate, and recognize sensory stimuli, and learning is often optimal in a multisensory environment. Currently used multisensory stimulation methods in stroke rehabilitation include motor imagery, action observation, training with a mirror or in a virtual environment, and various kinds of music therapy. Non-invasive brain stimulation has showed promising preliminary results in aphasia and neglect. Patient heterogeneity and the interaction of age, gender, genes, and environment are discussed. Randomized controlled longitudinal trials starting earlier post-stroke are needed. The advance in brain network science and neuroimaging enabling longitudinal studies of structural and functional networks are likely to have an important impact on patient selection for specific interventions in future stroke rehabilitation. It is proposed that we should pay more attention to age, gender, and laterality in clinical studies.

Keywords: motor imagery, virtual reality

\section{INTRODUCTION}

We live in a multisensory environment and the interaction between our genes and the environment shapes our brains. The brain has a large capacity for automatic simultaneous processing and integration of sensory information, and multisensory influences are integral to primary as well as higher order cortical operations (Ghazanfar and Schroeder, 2006). Combining information from different sensory modalities facilitates our ability to detect, discriminate, and recognize sensory stimuli (Driver and Noesselt, 2008; Shams and Seitz, 2008; Gentile et al., 2011). Non-invasive brain stimulation does not only affect the targeted local regions but also activity in remote interconnected regions. Although repetitive transcranial magnetic stimulation (rTMS) cannot directly target subcortical structures, the activity in thalamus can be modulated by stimulation of parietal cortex, an observation that open up new possibilities for studies of corticalsubcortical interactions in multisensory processing (Blankenburg et al., 2008, 2010). Multisensory enhancement of detection sensitivity for low-contrast visual stimuli by sounds reflects a brain network involving not only established multisensory and sensoryspecific cortex but also visual and auditory thalamus (Noesselt et al., 2010). Diffusion tensor imaging and tractography have enhanced the opportunity to study white matter tract networks and compare structural and functional connectivity in humans (Ciccarelli et al., 2008). Combining non-invasive brain stimulation with neuroimaging offers an opportunity to study causal relations between specific brain regions and individual cognitive and perceptual functions (Driver and Noesselt, 2008; Driver et al., 2009; Bolognini and Maravita, 2011; Zamora-López et al., 2011). Non-invasive brain stimulation techniques have the advantage that they can be used both as diagnostic tools and in treatment.

\section{MIRROR NEURONS, TRAINING WITH A MIRROR, AND ACTION OBSERVATION}

During intracellular recordings in macaque monkeys, premotor neurons that discharge both in association with performance of a motor task and when observing a human individual performing the same action were identified and named mirror neurons (Gallese et al., 1996). In addition to action understanding, mirror neurons have also proposed to be fundamental for imitation learning (Rizzolatti and Craighero, 2004) and for language (Rizzolatti and Arbid, 1998) and social interactions.

Activation of human primary motor cortex during action observation was first observed in a neuromagnetic study by Hari et al. (1998). In a following study on the temporal dynamics of the cortical representation for action (Nishitani and Hari, 2000), the left inferior frontal cortex, Brodmann's area (BA) 44, was activated first followed within $100-200 \mathrm{~ms}$ by activation of the left primary motor area (BA4) and 150-250 ms later by the right BA4. The data suggest that that left BA44 is the orchestrator of the human "mirror neuron system" and is strongly involved in action imitation. It was also shown that the reactivity of the human primary motor cortex was stronger during observation of live rather than video motor acts (Järveläinen et al., 2001).

The same motor neuron regions that are activated both when performing and when observing a movement are also activated prior to observing another persons action. This observation suggests that the mere knowledge of an upcoming movement is sufficient to excite one's own motor system, enabling people to anticipate, rather than react to, the action of others (Kilner et al., 2004). These and other studies have let to the suggestion that mirror neurons may be a product of associative learning (Catmur et al., 2009, 2011; Kilner et al., 2009a,b; Heyes, 2010). The associative learning hypothesis proposes that the mirror neurons are 
not innate but plastic, and can be transformed by sensorimotor learning and experience during life (Heyes, 2010; Catmur et al., 2011). Brain imaging studies suggest that areas responding to the observation and performance of actions are more widespread in the human brain and that multiple regions that process both sensory and motor information have the potential to contribute to mirror effects.

In a recent fMRI study 20 participants observed identical actions under different instruction context. A multi-voxel pattern analysis revealed unique patterns of activation in ventral premotor cortex and inferior parietal lobule across the difference contexts. The task was either to understand the actions, to identify the physical feature of the actions, or passively observe the action. The results showed that ventral premotor and inferior parietal areas respond differently to observed actions depending on the mindset of the observer (Molenberghs et al., 2012a).

A meta-analysis of 125 human fMRI studies that met strict inclusion and exclusion criteria revealed 14 separate clusters in which activation have been consistently attributed to brain regions with mirror properties encompassing 9 different Brodmann areas. These clusters were located in areas considered to show mirroring properties in the macaque such as the inferior parietal lobule, inferior frontal gyrus, and the adjacent ventral premotor cortex, but also the primary visual cortex, cerebellum, and parts of the limbic system. The findings suggest a core network of human brain regions that possess mirror properties associated with action observation and execution, with additional areas recruited during tasks that engage non-motor functions such as auditory, somatosensory, and affective components (Molenberghs et al., 2012b).

The temporal dynamics of the brain activation during the observation of a motor act and underlie the observers capacity to understand what the agent is doing and why, has been studied with high-density EEG neuroimaging (Ortique et al., 2010). Two volunteers were presented with two-frame video-clips, the first showed an object with or without context, the second frame showed a hand interacting with the object. Visual event-related potentials were recorded time-locked with the frame showing the hand-object interaction. The results revealed four major steps (1) bilateral posterior cortical activation, (2) a strong activation of the left posterior temporal and inferior parietal cortices with almost a disappearance of activation in the right hemisphere, (3) a significant increase of the activations of the right temporalparietal region with simultaneously co-activation of some areas in the left hemisphere, (4) a significant global decrease of cortical activity accompanied by activation in the orbitofrontal cortex. The interpretation of the authors was that the early left hemisphere involvement was due to the activation of a lateralized action observation/action execution network that mediates the understanding of the goal of object-directed motor acts (mirror mechanism), and that the successive right-hemisphere activation indicated an important role in understanding the intention of others.

Actions can be described at multiple levels including the kinematic level, the motor level, the goal level and the intention level, and there are thus multiple levels at which an observed action can be understood. The action observation network is unlikely to encode the more abstract levels of understanding such as the intention and the goal of the action (Kilner, 2011). Kilner argues that the ability to understand actions at these abstract levels is most likely encoded in the middle temporal gyrus and the more anterior regions of the inferior frontal gyrus in a ventral pathway.

That viewing the mirror reflection of movement of the unimpaired arm could improve functional recovery of the impaired (not visible) arm following stoke was first shown in a placebocontrolled pilot study by Altschuler et al. (1999). In training with a mirror, the patient's affected hand is hidden behind a mirror. Sathian et al. (2000) reported a case study using this approach to stroke rehabilitation in a patient with poor function of an arm due mainly to somatosensory deficits after stroke. Mirror therapy facilitated employment of a motor copy strategy involving bimanual movements and later "forced use" of the affected arm.

While moving the unaffected arm, that patient watches its mirror image as it were the affected arm, and viewing the mirror reflection facilitates ipsilateral motor cortex excitability (Garry et al., 2005). In 40 patients, included within 12 months post-stroke, hand function improved more after mirror therapy in addition to a conventional rehabilitation program after 4 weeks of treatment and at 6 months follow-up (Yavuzer et al., 2008). Thirty-six patients with severe hemiparesis because of a first-ever ischemic stroke in the middle cerebral artery territory were enrolled not more than 8 weeks after the stroke to an additional protocol of 6 weeks therapy $30 \mathrm{~min}$ a day, 5 days a week, with random assignment to either mirror therapy or an equivalent control therapy (Dohle et al., 2009). The distal functions of the arms improved more with mirror therapy. Furthermore, mirror therapy enhanced recovery of surface sensibility and stimulated recovery from hemineglect. Neither of there effects depended on the side of the damaged hemisphere. In a phase II randomized controlled trial with 40 chronic stroke patients (mean time post onset 3.9 years) motor functions improved more in the mirror than in the control groups (Michielsen et al., 2011). The improvement did not persist at follow-up, but fMRI results showed a shift in activation balance within the primary motor cortex toward the affected hemisphere in the mirror group only $(p<0.05)$.

Action observation has a positive impact on rehabilitation of motor deficits and is associated with a significant rise in activity in the bilateral ventral premotor cortex, bilateral superior temporal gyrus, the supplementary motor area, and the contralateral supramarginal gyrus in $\mathrm{fMRI}$, thus including regions that are not including in the mirror hypothesis (Ertelt et al., 2007). An extensive overlap of parietal networks activated during action execution and observation support that the entire distributed neural network responsible for the execution of action rather than the concept of "mirroring" may be needed for the understanding the actions of others (Tessari et al., 2007). The improvement lasted for at least 8 weeks after the end of the intervention (Ertelt et al., 2007). Disruptive TMS $(1 \mathrm{~Hz})$ over the ventral premotor cortex reduced the beneficial effect suggesting that the fMRI activation in premotor cortex during action observation was functionally relevant, at least for the beneficial effect that action observation exerts over motor training (Cattaneo et al., 2011). Neurophysiological data support that action observation is accompanied by specific and differential changes in cortico-motor excitability within the hand motor representation in the primary motor cortex (Celnik et al., 2008). 
Patients with parietal damage can show impairments in their ability to imitate or understand an observed action, but they may also have difficulties in monitoring early phases of their own movement planning. Both problems may occur after a parietal lesion. EEG and the readiness potential, RP, a marker of motor preparation which appears when preparing to observe an action (Kilner et al., 2004) were registered in patients with parietal lesions and in patients with a ventral premotor cortex lesion and with neurologically normal controls in an interesting recent study. All individuals were requested to watch passively a video showing an actor grasping a colored object that cued the subjects that the actor was about to move. Neurologically normal subjects and patients with a ventral premotor cortex lesion exhibited a significant RP prior to the observed action, whereas no such RP was observed in the patients with parietal lesions. The results indicate that parietal activity during action observation does not only or essentially reflect a mirroring process but rather involves an anticipatory process that may arises through prior learning and predictive mechanisms (Fontana et al., 2012).

Activation patterns in anterior regions of inferior frontal gyrus suggest dissociable operation when observing and executing actions, and caution should be exercised when claiming that activations in many locations during action observation indicate the operation of mirror neurons (Press et al., 2012).

\section{MOTOR IMAGERY}

Motor imagery accompanied by a voluntary inhibition of the actual movement activates regions that are involved in movement preparation and execution (Lotze and Cohen, 2006). Mental training has the advantage that it can start early, is easy to use and cost effective. That mental training can improve motor function and alter cortical representation areas is well documented in healthy individuals (Pascual-Leone et al., 2005; Nyberg et al., 2006; Olsson et al., 2008). Thirteen consecutively admitted patients between 4 weeks and 1 year post-stroke with stable motor deficits in their affected upper limbs received $1 \mathrm{~h}$ of therapy three times a week for 6 weeks. During the same period, eight patients participated in 10-min guided imagery sessions after each therapy session as well as practicing imagery at home twice each week. Therapy only remained the same but therapy + imagery group scores improved significantly (Page et al., 2001a,b). Chronic stroke patients were trained three times per week for 10 weeks and $\mathrm{fMRI}$ was performed before and after intervention. Post intervention fMRI showed a significant increase in activation to wrist flexion and extension of the affected hand in the premotor area and primary motor cortex on both sides, as well as in superior parietal cortex ipsilateral to the affected hand (Page et al., 2009). The positive effect remained 3 months after participation of the study (Page et al., 2011). It has recently been proposed that mental practice might also be of interest for reducing stroke-induced motor speech disorders (Page and Harnich, 2012).

Combined motor and mental training activate both the motor and the visual regions in fMRI (Nyberg et al., 2006). In addition, motor and mental training significant increased in tapping performance on an untrained sequence (transfer), and fMRI scanning indicated that the transfer effect involved the cerebellum. The conclusion was that combined motor and mental training improves motor flexibility via connections from both motor and cognitive systems to the cerebellum (Olsson et al., 2008).

In a program with home-based motor imagery training for gait rehabilitation 3 days a week for 6 weeks of patients with poststroke hemiparesis, starting 3 months or later after stroke onset, the gains were largely maintained 3 weeks after the trial (Dunsky et al., 2008). A recent Cochrane database systemic review concludes that mental practice in combination with other treatment appears more effective in improving upper extremity function than the other treatment alone, but that further studies are needed (Barclay-Goddard et al., 2011).

\section{VIRTUAL REALITY}

Virtual reality technologies provide multimodal, interactive, and realistic $3 \mathrm{D}$ environments with a high level of control of the parameters and applications that can be adjusted for each user and combined with other techniques (Broeren et al., 2008; Tsirlin et al., 2009). Greater change in velocity and walking distance both in the laboratory and in the community was obtained when the robot was coupled with virtual environments in gait training (Mirelman et al., 2008). Mixing several tasks in one session produced better retention than training only one task, and in acute and sub-acute stages of recovery it would be more effective to focus rehabilitation on restoration of impairment and avoid a premature emphasis on compensation (Huang and Krakauer, 2009; Da Silva Cameirao et al., 2011). Virtual-reality games may enhance the effect of robot training on attention, speed, force, precision, and timing in the arm (Takahashi et al., 2008). A recent meta-analysis to determine the added benefit of VR technology on upper arm motor recovery concluded that VR and video game applications are potentially useful technologies that can be combined with conventional rehabilitation for upper arm improvement in motor function (Saposnik et al., 2011).

Unilateral spatial neglect is present in almost $50 \%$ of patients with right-hemisphere stroke and has a negative impact on functional recovery after stroke. A virtual reality supermarket has been used both for assessment and treatment of neglect (Ansuini et al., 2006; Broeren et al., 2007; Rand et al., 2009). Assessment of spatial attention and neglect with a virtual wheelchair navigation task has shown promise as a sensitive, efficient measure of real-life navigation (Buxbaum et al., 2008). A three-dimensional virtual street program has been developed for assessment and training extra-personal neglect and enables outdoor mobilization (Kim et al., 2010). With an fMRI-compatible VR system interfaced with robots, movement tracking, and sensing glove systems it has been shown that VR spatial brain processing differs from brain fMRI in reality and activates additional brain areas (Adamovich et al., 2009). In evaluation of possible restoration effects caused by VR training it is therefore important to integrate information about the brain activation area networks elicited by the training in VR. Combining VR and fMRI in intact brains has confirmed differences and commonalities of brain processing in VR and demonstrated the benefit of fMRI as an evaluation tool for the mental processes involved in virtual environments (Beck et al., 2010). 


\section{NEGLECT}

Neglect is an important negative prognostic factor. Current concept of neglect is that it is not located to specific region but related to the attention networks. Connectivity in two largely separate attention networks located in dorsal and ventral fronto-parietal areas was assessed at acute and chronic stages of recovery in a longitudinal study of patients with spatial neglect following right hemispheric stroke. Connectivity in the ventral network, part of which was damaged, was diffusely disrupted and showed no recovery. In the structurally intact dorsal network the inter-hemispheric connectivity in posterior parietal cortex was acutely disrupted but fully recovered (Corbetta et al., 2005). A longitudinal study of patients with spatial neglect has further supported a network view in understanding neglect following right hemispheric stroke (He et al., 2007). Corbetta and Shulman (2011) have argued that neglect is better explained by the dysfunction of distributed cortical networks for the control of attention than by structural damage of specific brain regions. Ventral lesions in right parietal, temporal, and frontal cortex that cause neglect directly impair non-spatial functions partly mediated by a ventral fronto-parietal attention network. Structural damage in ventral cortex also induces physiological abnormalities of task-evoked activity and functional connectivity in a dorsal fronto-parietal network that controls spatial attention. The anatomy and right-hemisphere dominance of neglect follow from the anatomy and laterality of the ventral regions that interact with the laterality of the ventral regions that interact with the dorsal attention network. This and other studies indicate that neglect is better explained by the dysfunction of distributed cortical networks for the control of attention than by structure damage of specific brain regions (Corbetta and Shulman, 2011; Urbanski et al., 2011). Perception-attention deficits showed the most variability in the course of recovery making them prime candidates for intervention (Rengachary et al., 2011).

The aim with non-invasive stimulation for neglect is to reduce the imbalance between the two hemispheres. Most studies have so far done this by reducing the activity in the intact posterior parietal cortex with low-frequency TMS. An alternative approach is to stimulate the damaged side. Both effect of cathodal transcranial direct current stimulation (tDCS) applied over the intact posterior parietal cortex and the facilitating effect of anodal tDCS applied over the damaged posterior parietal cortex reduce symptoms of visuospatial neglect (Sparing et al., 2009). For extensive reviews on the different methods used to ameliorating spatial neglect with TMS and tDCS see Fierro et al., 2006; Cazzoli et al., 2010; Hesse et al., 2011).

Another non-invasive stimulation that may have a longer effect is continuous theta-burst stimulation (cTBS). When applied over the left posterior parietal cortex in 10 sessions over a 2 -week period it accelerated recovery of hemispatial neglect. Hyperexcitability of the left parieto-frontal circuit was reduced following treatment with real but not sham cTBS, and the improvement remained 1 month after the treatment (Koch et al., 2012).

The potential role of the emotional state in modulating awareness after stroke has been tested in patients with chronic visual neglect. The visual awareness increased when tasks were performed under preferred music conditions relative to un-preferred music or silence (Soto et al., 2009). Emotional responses were associated with enhanced activity in the orbitofrontal cortex and cingulate gyrus. Improved awareness of contralateral (left) targets and a strong functional coupling between emotional areas and attention related brain regions was noted in spared areas of the parietal cortex and early visual areas in the right hemisphere. These findings suggest that positive affect, generated by preferred music, can enhance attention and decrease visual neglect, most likely due to enhancing attention.

\section{NON-INVASIVE CORTICAL STIMULATION IN LANGUAGE}

Transcranial direct current stimulation over Broca's region improves phonetic and semantic fluency in healthy individuals (Cattaneo et al., 2011). Significant improved naming accuracy has been obtained with anodal rDCS over the left frontal cortex in chronic stroke (Baker et al., 2010). Inhibiting the right Broca's homolog area by cathodal tDCS also improves picture naming in patients with chronic aphasia (Kang et al., 2011).

Sub-acute stroke patients with non-fluent aphasia were randomly divided into three groups that received either anodal tDCS applied to the left superior temporal gyrus, sham tDCS, or cathodal tDCS to the right superior temporal gyrus. All patients received conventional speech and language therapy and all patients improved. However, auditory verbal comprehension improved significantly more in patients treated with a cathode, as compared to patients in the other groups (You et al., 2011).

Low-frequency $(1 \mathrm{~Hz})$ rTMS applied to the homolog to Broca's area 20 min per day for 10 days have been used in a series of studies applied to the homolog to Broca's area. Sustained language improvement up to 8 months subsequent to TMS stimulation were observed in 12 non-fluent persons with aphasia 2-6 years poststroke (Barwood et al., 2011a). In a following study, six real and six sham placebo stimulations were applied with effect only in the real stimulation groups (Barwood et al., 2011b). The electrophysiological correlates associated with the application of rTMS were studied by recording the semantic based N400 ERP measures at baseline, 1 week and 2 months subsequent to stimulation. The N400 ERP represents the capacity of rTMS to modulate neuronal language networks and measures of lexical-semantic function in participants with non-fluent aphasia. No difference was observed between baseline and 1 week but significant effect was obtained at 2 months. The authors proposed that time may be an important factor in brain reorganization subsequent to rTMS (Barwood et al., 2011c).

Melodic intonation therapy for severe non-fluent aphasia is an old method that has been systematically applied and evaluated in recent years (Norton et al., 2009). It includes three components; melodic intonation, intense training $1.5 \mathrm{~h}$ /day 5 days a week for several weeks, and simultaneous rhythmic tapping with the left hand (corresponding to the right unaffected hemisphere) to prime the sensorimotor and premotor cortices on the right side for articulation. It may lead to remodeling of the right arcuate fasciculus, a fiber bundle that combines the anterior and posterior language area in the left hemisphere, indicating that plasticity can be induced in the contralateral homolog tract in the unaffected hemisphere (Schlaug et al., 2009). Combining melodic intonation therapy with anodal tDCS in the posterior inferior frontal gyrus of the right-hemisphere enhanced the beneficial effect of 
the training (Hamilton et al., 2011; Vines et al., 2011). For an extensive review on non-invasive brain stimulation in post-stroke aphasia, see Schlaug et al. (2011).

\section{ACTION, GESTURES, AND LANGUAGE}

Action, gestures, and language are closely related in the human brain (Rizzolatti and Arbid, 1998; Nishitani et al., 2005; Gentilucci and Corballis, 2006; Corballis, 2009). Broca's area, that traditionally was looked upon as an exclusive language area, is now considered to detect and represent complex hierarchical dependencies regardless of modalities of use including gestures, action, and music (Fadiga et al., 2009). It has been proposed to play an important role both in semantic retrieval or selection as part of a language comprehension system, and in action recognition as part of a mirror or observation-execution matching system (Skipper et al., 2007a). A network analysis of neuroimaging data has shown that interactions involving Broca's area and other cortical areas are weakest when spoken language was accompanied by meaningful speech-associated gestures, and strongest when spoken language was accompanied by self-grooming hand movement or by no hand movements (Skipper et al., 2007b). Symbolic gestures and spoken language are processed by a common neural system (Xu et al., 2009) and gestures may facilitate word retrieval in aphasia (Raymer et al., 2006). Being able to see the face and hand movements of a speaker facilitates language comprehension. Audiovisual speech perception activates network of brain regions that include cortical motor areas involved in planning and executing of speech production. When gesture accompany speech, the motor system interact with language comprehension areas to determine the meaning of the gestures, suggesting that the cortical networks underlying language comprehension are being dynamically organized by the type of contextual information available to listeners during face to face communication (Skipper et al., 2009). Co-speech gestures influence neural activity in brain regions associated with processing semantic information (Dick et al., 2009). Audiovisual comprehension activates the same fronto-temporo-parietal network of regions known for their contribution to speech production and perception. However, there are age-related differences in the functional interaction among these regions (Dick et al., 2010). Speech and co-speech gestures are usually produced together and gestures and not unambiguously understood without speech. On the contrary, pantomimes are not necessarily produced together with speech and can be easily understood without speech. Posterior STS/MTG and LIFG are differentially involved in multimodal integration, crucially depending upon the semantic relationship between the input streams. IMITATE, an intensive computer-based treatment for aphasia based on action observation and imitation, has been introduced but no results are available at this time (Lee et al., 2010).

\section{MUSIC THERAPY}

Music is a multimodal stimulus that activates many brain structures related to sensory processing, attention, and memory, and can stimulate complex cognition and multisensory integration (Zatorre et al., 2007; Koelsch, 2009; Thaut et al., 2009). The modular view of music processing with music-specific neuronal regions and networks is challenged by the alternative view that there is a significant overlap between neuronal structures used for language and music processing. There are evidence for shared neural processing resources between the phonological/semantic aspects of language and the melodic/harmonic aspects of music (Patel, 2003, 2008; Koelsch et al., 2004; Patel and Iversen, 2007; Besson et al., 2011).

Listening to rhythm activates motor and premotor cortices (Zatorre et al., 2007; Chen et al., 2008; Bengtsson et al., 2009), and rhythmic auditory stimulation and musical motor feedback can improve gait and arm training (Schauer and Mauritz, 2003; Thaut et al., 2007). Music-supported finger and arm training that significantly improved function is accompanied by electrophysiological changes, indicating better cortical connectivity and improved activation of the motor cortex (Altenmüller et al., 2009). In a community-based stroke intervention program combining rhythmic music and a specialized rehabilitation program during 8 weeks starting 44 days post-stroke, gait velocity, symmetry, and stride length improved more than in the control groups. Stroke patients reported more positive moods and increased frequency and quality of interpersonal relationships compared to the control group (Jeong and Kim, 2007).

Daily listening to self-selected music may improve verbal memory and attention after stroke (Särkämö et al., 2008). Musical training has extensive effects on the brain. One aspect that may be relevant for stroke rehabilitation is that musicians have enhanced subcortical auditory and audiovisual processing of speech and music (Musacchia et al., 2007, 2009). Musical experience shapes brainstem encoding of linguistic pitch patterns (Wong et al., 2007), and musical training results in enhanced ability to hear speech in background noise (Parbery-Clark et al., 2009; Shahin, 2011; Strait and Kraus, 2011). Auditory attention is important for the development and maintenance of language-related skills, and musical training may aid in the prevention, habilitation, and remediation of individuals with a wide range of attentionbased language, listening, and learning impairments (Strait and Kraus, 2011). The capacity to hear speech-in-noise is reduced in aging (Musacchia et al., 2009; Zamora-López et al., 2009). Significant improvements in speech-in-noise perception have been obtained in adult individuals with no prior music training with a training program that incorporated cognitively based listening exercises to improve speech-in-noise perception (Song et al., 2011). The beneficial effect was retained 6 months after the end of the study. Problem with hearing speech-in-noise is common after stroke and has considerable social consequences. It would be interesting to study if a similar program would have any effect post-stroke.

A bi-hemispheric network for vocal production is activated regardless of whether the words/phrases are intoned or spoken (Ozdemis et al., 2006), and words and melody are intertwined in perception of sung words. Some patients with aphasia are able to sing the text of a song while they are unable to speak the same text. The familiarity with the song seems to be important (Straube et al., 2008). Singing in synchrony with an auditory model (choral singing) is more effective than choral speech in improving word intelligibility (Racette et al., 2006; Gordon et al., 2010). 


\section{AGE, GENDER, AND LATERALITY}

Recent developments in the quantitative analysis of complex networks, based largely on graph theory, have been rapidly translated to studies of brain network organization (Sporns et al., 2004, 2007; Bullmore and Sporns, 2009; Honey et al., 2009; Sporns, 2011). The networks span multiple spatial scales, from individual cells to cognitive systems and behavior.

Large cross-sectional study on healthy individuals ranging in age from 18 to 95 years have indicated age-related reduction in overall connectivity with age, with decreased local efficiency from the parietal and occipital to frontal and temporal neocortex in older brains. Women showed greater overall cortical connectivity and the underlying organization of their cortical networks was more efficient both locally and globally. It is proposed that it should be mandatory to take gender into account when designing experiments or interpreting results of brain connectivity/network in health and disease (Gong et al., 2009, 2011). Reduced correlations were associated with disruptions in white matter integrity and poor cognitive performance across a range of domains. Diffusion tensor imaging studies similarly indicate age-related changes in the prefrontal white matter (Malykhin et al., 2011).

The performance of the dominant arm/hand is most accurate when reaching from one fixed starting point to multiple targets, and performance with the non-dominant hand is most accurate when reaching toward a single target from multiple start locations (Sainburg and Duff, 2006; Wang and Sainburg, 2007). Studies on patients with stroke have shown differences that reflect these differences (Schaefer et al., 2007, 2009, 2011). The side of the lesion influence bilateral activation in chronic post-stroke hemiparesis (Lewis and Perreault, 2007) and the arm use after left or right hemiparesis is influenced by hand preference (Rinehart et al., 2008). The inter-hemispheric inhibition is stronger from the dominant to the non-dominant side than in the opposite direction. A similar pattern, but reduced lateralization for inter-segmental coordination is seen in lefthanders, possibly due to environmental pressure for right-handed manipulations (Przybyla et al., 2012). Modulating activity in the motor cortex affect performance for the two hands differently depending on which hand is stimulating. In two right-handed age groups, $20-40$ years and 60-80 years of age, measures of final position accuracy, precision and trajectory linearity showed robust asymmetries in the left and right arms only in the young adults (Przybyla et al., 2011).

Gene expression profiles assessed in the hippocampus, superior-frontal gyrus, and postcentral gyrus of 55 cognitive intact individual aged 20-99 years demonstrated clear gender differences in brain aging (Berchtold et al., 2008). Different categories of genes were predominantly affected in males vs. females, and different regions of the forebrain exhibited substantially different gene profile changes with age. Prominent change occurred in the sixth to seventh decade across cortical regions particularly in males. Globally across all brain regions, males showed more gene changes than females.

\section{INDIVIDUAL DIFFERENCES IN BEHAVIOR AND COGNITION}

A wide range of basic and higher cognitive function, including perception, motor control, memory, and the ability to introspect, can be predicted from the local structure of gray and white matter as assessed by voxel-based morphometry or diffusion tensor imaging (Kanai and Rees, 2011). The authors propose that it would be more useful to use inter-individual differences as a source of information to link human behavior and cognition to brain anatomy rather than regard them as "noise" as is common today. Individual data may show unexpected results that can be the basis for new hypotheses that can be and tested. Age independent relationships between white matter anatomy and cognitive ability are found in healthy adult populations. Studies using diffusion-weighted magnetic resonance imaging support that inter-individual variation in white matter structure has consequences for behavior and may predict how well patients will respond to specific interventions (Johansen-Berg, 2010).

Genetic polymorphisms contribute to the increasing heterogeneity of cognitive function in old age. Brain-derived growth factor (BDNF) has a critical role in activity-dependent modulation of synaptic plasticity in human motor cortex. A common single nucleotide polymorphism (BDNF val66met) reduces secretion of BDNF, and the activity related cortical plasticity in response to motor training (Kleim et al., 2006). It is associated with greater error and poorer retention in short-term motor learning (McHughen et al., 2010) and reduces cognitive abilities in the elderly (Cheeran et al., 2008; Miyajima et al., 2008). Genetic differences may have increasingly large effect on cognition when the cognitive resources are reduced in aging. Thus the effect of the catechol-O-methyltransferase (COMT) gene heterogeneity on cognitive performance is magnified in old age and interacts with BDNF gene heterogeneity (Lindenberger et al., 2008).

Aging is associated with a progressive decline of perception, motor behavior and cognition, and memory functions (Dinse, 2005; Persson et al., 2006). However, there is considerable individual variation and high physical and cognitive activities may reduce the aging-related decline (Kramer and Erickson, 2007). An interesting study on elderly individuals with multi-year dancing

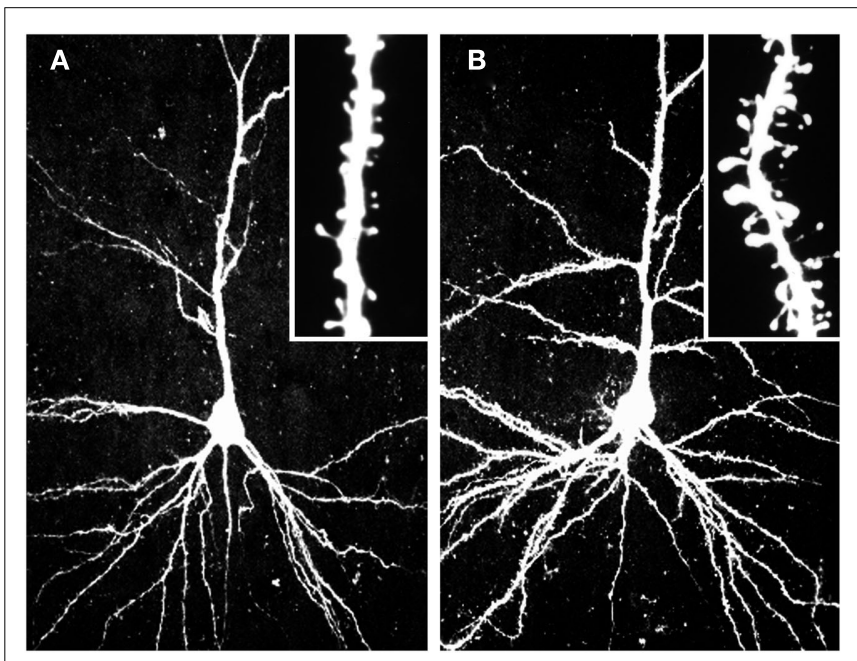

FIGURE 1 | Dendritic branching and spines in pyramidal neurons in parietal cortex in rats housed in standard laboratory cages $(A)$ and rats in enriched environment with opportunity for various activities (B), Johansson and Belichenko (2002). 
activities showed highly significant superior sensory, motor, and cognitive performance control group. Dance clearly involve multisensory stimulation and interactions that in addition to training physical activity, include motor coordination and balance, emotional stimulation, social interaction, sensorimotor stimulation, and clearly creates an enriched environment (Kattenstroth et al., 2010).

There is also substantial evidence from animal studies that a stimulating environment, before and/or after a stroke can reduced the impact of an ischemic lesion (Johansson, 2000, 2004). Figure 1 shows the dendritic morphology of pyramidal neurons in layer II/III in rat housed in standard (Figure 1A) or in an enriched environment (Figure 1B) as viewed in confocal laser scanning microscopy after microinjection of Lucifer yellow into the neurons (Johansson and Belichenko, 2002). Post-ischemic enriched environment also improves motor and cognitive functions, stimulates neurogenesis in the subventricular zone (Komitova et al., 2005), and reduces secondary thalamic atrophy after grafting (Mattsson et al., 1997).

\section{CONCLUDING REMARKS}

Stroke unit care is the only treatment that so far has been shown to have a major impact on the outcome after stroke. More patients can return home early, and the need for institutional care is reduced (Dewey et al., 2007; Stroke Unit Trialists' Collaboration, 2007; Indredavik, 2009). The benefit of stroke units compared to general wards is most likely a combination of optimal medical and nursing care, well functional teams, task oriented, and

\section{REFERENCES}

Adamovich, S. V., Fluet, G. G., Merians, A. S., and Tunik, E. (2009). A virtual reality-based system integrated with fMRI to study neural mechanisms of action observation-execution: a proof of concept study. Restor. Neurol. Neurosci. 27, 209-923.

Altenmüller, E., Marco-Pallares, J., and Münte, T. F. (2009). Neural reorganization underlies improvement in stroke-induced motor dysfunction by music-supported therapy. Ann. N. Y. Acad. Sci. 1169, 395-405.

Altschuler, E. L., Wisdom, S. B., Stone, L., Foster, C., Galasko, D., Llewellyn, D. M. E., and Ramachandran, V. S. (1999). Rehabilitation of hemipares after stroke with a mirror. Lancet 353, 2035-2036.

Ansuini, C., Pierno, A. C., Lusher, D., and Castiello, U. (2006). Virtual reality applications for the remapping of space in neglect patients. Restor. Neurol. Neurosci. 24, 431-441.

Baker, J. M., Rorden, C., and Fridriksson, J. (2010). Using transcranial direct-current stimulation to treat stroke patients with aphasia. Stroke 41, 1229-1236.

Barclay-Goddard, R. E., Stevenson, T. J., Poluha, W., and Thalman, L. (2011).
Mental practice for treating upper extremity deficits in individuals with hemiparesis after stroke. Cochrane Database Syst. Rev. 5, CD005950.

Barker-Collo, S. L., Feigin, V. L., Lawes, C. M., Parag, V., Senior, H., and Rodgers, A. (2009). Reducing attention deficits after stroke using attention process training: a randomized controlled trial. Stroke 40, 3293-3298.

Barwood, C. H., Murdoch, B. E., Whelan, B. M., Lloyd, D., Riek, S., O'Sullivan, J. D., Coulthard, A., and Wong, A., Aiken, P., and Hall, G. (2011a). The effects of low frequency repetitive transcranial magnetic stimulation (rTMS) and sham condition rTMS on behavioral language in chronic non-fluent aphasia. Short term outcomes. NeuroRehabilitation 28, 113-128.

Barwood, C. H., Murdoch, B. E., Whelan, B. M., Lloyd, D., Riek, S., O'Sullivan, J. D., Coulthard, A., and Wong, A. (2011b). Improved language performance subsequent to low-frequency rTMS in patients with chronic nonfluent aphasia post-stroke. Eur. J. Neurol. 18, 935-943. lan, B. M., Lloyd, D., Riek, S., O'Sullivan, J. D., Coulthard, A.,
Barwood, C. H., Murdoch, B. E., Whe-

for the individual meaningful training in an environment that gives them confidence, stimulation, and motivation (Johansson, 2011). Cognitive rehabilitation programs starting early after stroke are essential to establish whether attention-training (Barker-Collo et al., 2009), or non-invasive cortical stimulation can lead to better social adjustment and quality of life post-stroke. Working memory and attention are important in most cognitive activities. In pilot studies, anodal tDCS over the left dorsolateral prefrontal cortex has been reported to enhance working memory (Jo et al., 2009) and to improve post-stroke attention decline (Kang et al., 2009).

Progress of time is an independent covariate that reflects spontaneous recovery of function during the first months after a stroke. To avoid the confounding effect of time (Kwakkel et al., 2006) most studies on testing new rehabilitation methods have been performed several months after stroke. Optimal benefits for the patients and the society would supposedly be obtained by successful intervention in the sub-acute phase as indicated by the beneficial effect on motor outcome in stroke units (Dewey et al., 2007; Indredavik, 2009). Rehabilitation program may require different therapy protocols in acute and chronic stages of recovery, and we need to know the optimal time for specific interventions.

The progress in research on cortical network reorganization after stroke (Wang et al., 2010; Grefkes and Fink, 2011; Westlake and Nagarajan, 2011) will increase our possibilities to test hypotheses related to treatment and outcome. One important question concerns the optimal time for starting non-invasive brain stimulation for cognitive functions. The optimal time and stimulation location may vary with the time post-stroke.

and Wong, A. (2011c). Modulation of N400 in chronic non-fluenct aphasia using low frequency repetitive transcranial magnetic stimulation (rTMS). Brain Lang. 116, 125-135.

Beck, L., Wolter, M., Mungard, N. F., Vohn, R., Staedtgen, M., Kuhlen, T., and Sturm, W. (2010). Evaluation of spatial processing in virtual reality using functional magnetic resonance imaging (fMRI). Cyberpsychol. Behav. Soc. Netw. 13, 211-215.

Bengtsson, S. L., Ullén, F., Ehrsson, H. H., Hashimoto, T., Kito, T., Naito, E., Forssberg, H., and Sadato, N. (2009). Listening to rhythms activate motor and premotor cortices. Cortex 45, 62-71.

Berchtold, M. C., Cribbs, D. H., Coleman, P. D., Rogers, J., Head, E., Kim, R., Beach, T., Miller, C., Troncoso, J., Trojanowski, J. Q., Zielke, H. R., and Cotman, C. W. (2008). Gene expression changes in the course of normal brain aging are sexually dimorphic. Proc. Natl. Acad. Sci. U.S.A. 105, 15605-15610.

Besson, M., Chobert, J., and Marie, C. (2011). Transfer of training between music and speech: common processing, attention, and memory. Front. Psychol. 2:94, 1-12.
Blankenburg, F., Ruff, C. C., Bestmann, S., Bjoertomt, O., Eshel, N., Josephs, O., Weiskopt, N., and Driver, J. (2008). Interhemispheric effect of parietal TMS on somatosensory response confirmed directly with concurrent TMS-fMRI. J. Neurosci. 28, 13202-13208.

Blankenburg, F., Ruff, C. C., Bestmann, S., Bjoertomt, O., Josephs, O., Deichmann, R., and Driver, J. (2010). Studying the role of human parietal cortex in visuospatial attention with concurrent TMS-fMRI. Cereb. Cortex 20, 2702-2711.

Bolognini, N., and Maravita, A. (2011). Uncovering multisensory processing through non-invasive brain stimulation. Front. Psychol. 2:46. doi:10.3389/fpysg2011.00046

Broeren, J., Claesson, L., Goude, D., Rydmark, K., and StibrantSunnerhagen, K. S., and Rydmark, M. (2007). Neglect assessment as an application of virtual reality. Acta Neurol. Scand. 116, 157-163.

Broeren, J., Samuelsson, H., StibrantSunnerhagen, K., Blomstrand, C., and Rydmark, M. (2008). Virtual activity in an activity centre for community dwelling persons with stroke; the possibility of $3 \mathrm{D}$ computer games. Cerebrovasc. Dis. 26, 289-296. 
Bullmore, E., and Sporns, O. (2009). Complex brain networks; graph theoretical analysis of structural and functional systems. Nat. Rev. Neurosci. 10, 186-198.

Buxbaum, L. J., Palermo, M. A., Mastrogiovanni, D., Read, M. S., RosenbergPitonyak, E., Rizzo, A. A., and Coslett, H. B. (2008). Assessment of spatial attention and neglect with a virtual wheelchair navigation task. J. Clin. Exp. Neurosphychol. 30, 650-660.

Catmur, C., Mars, R. B., Rushworth, M. F., and Heyes, C. (2011). Making mirrors: premotor cortex stimulation enhances mirror and countermirror facilitation. J. Cogn. Neurosci. 23, 2352-2362.

Catmur, C., Walsh, V., and Heyes, C. (2009). Associative sequence learning: the role of experience in the development of imitation and the mirror system. Philos. Trans. R. Soc. Lond. B Biol. Sci. 364, 2369-2380.

Cattaneo, Z., Pizoni, A., and Papagno, C. (2011). Transcranial direct current stimulation over Broca's region improves phonemic and semantic fluency in healthy individuals. $\mathrm{Neu}$ roscience $183,64-70$.

Cazzoli, D., Muri, R. M., Hess, C. W., and Nyffeler, T. (2010). Treatment of hemispatial neglect by means of rTMS - a review. Restor. Neurol. Neurosci. 28, 499-510.

Celnik, P., Webster, B., Glasser, D. M., and Cohen, L. G. (2008). Effects of action observation on physical training after stroke. Stroke 39, 1814-1820.

Cheeran, B., Tallelli, P., Mori, F., Koch, G., Suppa, A., Edwards, M., Houlden, H., Bhatia, K., Greenwood, R., and Rothwell, J. C. (2008). A common polymorphism in the brain-derived neurotrophic factor gene (BDNF) modulates human cortical plasticity and the response to rTMS. J. Physiol. 586, 5717-5725.

Chen, J. L., Penhune, V. B., and Zatorre, R. J. (2008). Listening to musical rhythms recruits motor regions of the brain. Cereb. Cortex 18, 2844-2854.

Ciccarelli, O., Catani, M., JohansenBerg, H., Clark, C., and Thompson, A. (2008). Diffusion-based tractography in neurological disorders: concepts, applications, and future deveopments. Lancet Neurol. 7, 715-727.

Corballis, M. C. (2009). Language as gesture. Hum. Mov. Sci. 28, 556-565.

Corbetta, M., Kincade, M. J., Lewis, C., Snyder, A. Z., and Sapir, A. (2005). Neural basis and recovery of spatial attention deficits in spatial neglect. Nat. Neurosci. 8, 1603-1610.

Corbetta, M., and Shulman, G. L. (2011). Spatial neglect and attention networks. Annu. Rev. Neurosci. 34, 569-599.

Da Silva Cameirao, M., Bermúdez, I., Badia, S., Duarte, E., and Verschure, P. F. (2011). Virtual reality based rehabilitation speeds up functional recovery of the upper extremities after stroke: a randomized controlled pilot study in the acute phase of stroke using the rehabilitation gaming system. Restor. Neurol. Neurosci. 29, 287-298.

Dewey, H. M., Sherry, L. J., and Coller, M. E. (2007). Stroke rehabilitation 2007: what should it be? Int. J. Stroke 2, 191-200.

Dick, A. S., Goldin-Medow, S., Hasson, U., and Skipper, J. L., and Small, S. L. (2009). Co-speech gestures influence neural activity in brain regions associated with processing semantic information. Hum. Brain Mapp. 30, 3509-3526.

Dick, A. S., Solodkin, A., and Small, S. L. (2010). Neural development for audiovisual speech comprehension. Brain Lang. 114, 101-114.

Dinse, H. R. (2005). Treating the aging brain: cortical reorganization and behavior. Acta Neurochir. Suppl. 93, 79-84.

Dohle, C., Püllen, J., Nakaten, A., Küst, J., Riezt, C., and Karbe, H. (2009). Mirror therapy promotes recovery from severe hemiparesis: a randomized controlled trial. Neurorehabil. Neural Repair 23, 209-217.

Driver, J., Blankenburg, F., Bestmann, S., Vanduffel, W., and Ruff, C. C. (2009). Concurrent brain-stimulation and neuroimaging for studies of cognition. Trends Cogn. Sci. (Regul. Ed.) 13, 319-327.

Driver, J., and Noesselt, T. (2008). Multisensory interplay reveals crossmodel influences on sensory-specific brain regions, neural responses, and judgments. review. Neuron 57, 11-23.

Dunsky, A., Dickstein, R., Marcovitz, E., Levy, S., Deutsch, J. E. (2008). Home-based motor imagery training for gait rehabilitation of people with chronic poststroke hemiparesis. Arch. Phys. Med. Rehabil. 89, 1580-1588.

Ertelt, D., Small, S., Solodkin, A., Dettmers, S., McNamara, A., Binkofski, F., and Buccino, G. (2007). Action observation has a positive impact on rehabilitation of motor deficits after stroke. Neuroimage 36, T164-T173.

Fadiga, L., Craighero, L., and D’Ausilio, A. (2009). Broca's area in language, action and music. Ann. N. Y. Acad. Sci. 1169, 448-458.

Fierro, B., Brighina, F., and Bisiach, E. (2006). Improving neglect with TMS. Behav. Neurol. 17, 169-176.

Fontana, A. P., Kilner, J. M., Rodrigues, E. C., Joffily, M., Nighoghossian, N., Vargas, C. D., and Sirigu, A. (2012) Role of the parietal cortex in predicting incoming actions. Neuroimage 59, 556-564.

Gallese, V., Fadiga, L., Fogassi, L., and Rizzolatti, G. (1996). Action recognition in the premotor cortex. Brain 119, 593-609.

Garry, M. I., Loftus, A., and Summers, J. J. (2005). Mirror, mirror on the wall: viewing a mirror reflection of unilateral hand movements facilitates ipsilateral M1 excitability. Exp. Brain Res. 163, 118-122.

Gentile, G., Petkola, V. I., and Ehrsson, H. H. (2011). Integration of visual and tactile signals from the hand in the human brain: an FMRI study. J. Neurophysiol. 105, 910-922.

Gentilucci, M., and Corballis, M. C. (2006). From manual gestures to speech: a gradual transition. Neurosci. Biobehav. Rev. 30, 949-960.

Ghazanfar, A. A., and Schroeder, C. E. (2006). Is neocortex essentially multisensory? Trends Cogn. Sci. (Regul. Ed.) 10, 278-285.

Gong, G., He, Y., and Evans, A. C. (2011). Brain connectivity: gender makes a difference. Age- and gender-related differences in the cortical anatomical network. Neuroscientist 17, 575-591.

Gong, G., Rosa-Neto, P., Carbonell, F., Chen, Z. J., He, Y., and Evens, A. C. (2009). Age- and genderrelated differences in the cortical anatomical network. J. Neurosci. 29, 15684-15693.

Gordon, R. L., Schön, D., Magne, C., Astésano, C., and Besson, M. (2010). Words and melody are intertwined in perception of sung words: EEG and behavioral evidence. PLoS ONE 5, e9889. doi:10.1371/journal.pone.0009889

Grefkes, C., and Fink, G. R. (2011) Reorganization of cerebral networks after stroke: new insights from neuroimaging with connectivity approaches. Brain 134, 1264-1276.

Hamilton, R. H., Chrysikou, E. G., and Coslett, B. (2011). Mechanisms of aphasia recovery after stroke and the role of noninvasive brain stimulation. Brain Lang. 118, 40-50.

Hari, R., Fross, N., Avikainen, S., Kirveskari, E., Salenius, S., and Rizzolatti, G. (1998). Activation of human primary motor cortex during action observation: a neuromagnetic study. Proc. Natl. Acad. Sci. U.S.A. 95, 15061-15065.

He, B. J., Snyder, A. Z., Vincent, J. L., Epstein, A., Shulman, G. L., and Corbetta, M. (2007). Breakdown of functional connectivity in frontoparietal networks underlies behavioral deficits in spatial neglect. $\mathrm{Neu}$ ron 53, 905-918.

Hesse, M. D., Sparing, R., and Fink, G. R. (2011). Ameliorating spatial neglect with noninvasive brain stimulation: from pathophysiological concepts to novel treatment strategies. $\mathrm{Neu}$ ropsychol. Rehabil. 21, 676-702.

Heyes, C. (2010). Where do mirror neurons come from? Neurosci. Biobehav. Rev. 34, 575-583.

Honey, C. J., Sporns, O., Cammoun, L., Gigandet, X., Thiran, J. P., Meuli, R., and Hagmann, P. (2009). Predicting human resting-state functional connectivity from structural connectivity. Proc. Natl. Acad. Sci. U.S.A. 106, 2035-2040.

Huang, V. S., and Krakauer, J. W. (2009). Robotic neurorehabilitation: a computational motor learning perspective. J. Neuroeng. Rehabil. 25, 6, 5.

Indredavik, B. (2009). Stroke unit care is beneficial both for the patient and for the health service and should be widely implemented. Stroke 40, $1-2$.

Järveläinen, J., Schürmann, M., Avikainen, S., and Hari, R. (2001) Stronger reactivity of the human primary motor cortex during observation of live rather than video motor acts. Neuroreport 12, 3493-3495.

Jeong, S., and Kim, M. T. (2007). Effects of a theory-driven music and movement program for stroke survivors in a community setting. Appl. Nurs. Res. 20. 125-131.

Jo, J. M., Kim, Y. H., Ko, M. H., Ohn, S. H., Joen, B., and Lee, K. H. (2009). Enhancing the working memory of stroke patients using tDCS. Am. J. Phys. Med. Rehabil. 88, 404-409.

Johansen-Berg, H. (2010). Behavioral relevance of variation in white matter microstructure. Curr. Opin. Neurol. 23, 351-358.

Johansson, B. B. (2000). Brain plasticity and stroke rehabilitation. the Willis lecture. Stroke 31, 223-230.

Johansson, B. B. (2004). Functional and cellular effects of environmental enrichment after experimental brain infarcts. Restor. Neurol. Neurosci. 22, 163-174.

Johansson, B. B. (2011). Current trends in stroke rehabilitation. A review with focus on brain plasticity. Acta Neurol. Scand. 123, 147-159. 
Johansson, B. B., and Belichenko, P. V. (2002). Neuronal plasticity and dendritic spines: effect of environmental enrichment on intact and postischemic rat brain. J. Cereb. Blood Flow Metab. 22, 89-96.

Kanai, R., and Rees, G. (2011). The structural basis of inter-individual differences in human behaviour and cognition. Nat. Rev. Neurosci. 12, 231-242.

Kang, E. K., Baek, M. J., Kim, S., and Paik, N. J. (2009). Non-invasive cortical stimulation improves poststroke attention decline. Restor. Neurol. Neurosci. 27, 645-650.

Kang, E. K., Kim, Y. K., Sohn, H. M., Cohen, L. G., and Paik, N. J. (2011). Improved picture naming in aphasia patients treated with cathodal tDCS to inhibit the right Broca's homologue area. Restor. Neurol. Neurosci. 29, 141-152.

Kattenstroth, J.-C., Kolankowska, I., Kalisch, T., and Dinse, H. R. (2010). Superior sensory, motor, and cognitive performance in elderly individuals with multi-year dancing activities. Front. Aging Neurosci. 2:31. doi:10.3389/fnagi.2010.00031

Kilner, J. M. (2011). More than one pathway to action understanding. Trends Cogn. Sci. (Regul. Ed.) 15, 352-357.

Kilner, J. M., Marchant, J. L., and Frith, C. D. (2009a). Relationship between activity in human primary motor cortex during action observation and the mirror neuron system. PLoS ONE 4, e 4925. doi:10.1371/journal.pone. 0004925

Kilner, J. M., Neal, A., Weiskopf, N., Friston, K. J., and Frith, C. D. (2009b). Evidence for mirror neurons in human inferior frontal gyrus. J. Neurosci. 29, 10153-10159.

Kilner, J. M., Vargas, C., Duval, S., Blakemore, S. J., and Sirigu, A. (2004). Motor activation prior to observation of a predicted movement. Nat. Neurosci. 7, 1299-1301.

Kim, D. Y., Ku, J., Chang, W. H., Park, T. H., Lim, J. Y., Han, K., Kim, I. Y., and Kim, S. I. (2010). Assessment of post-stroke extrapersonal neglect using a three-dimensional immersive program. Acta Neurol. Scand. 121, 171-177.

Kleim, J. A., Cham, S., Pringle, E., Schallert, K., Procaccio, V., Jimenez, R., and Cramer, S. C. (2006). BDNF val66met polymorphism is associated with modified experiencedependent plasticity in human motor cortex. Nat. Neurosci. 7, 735-737.

Koch, G., Bonni, S., Giacobbe, V., Bucci, G., Basile, B., Lupo, F., Versace,
V., Bozzali, M., and Caltagirone, C. (2012). Theta-burst stimulation of the left hemisphere accelerates recovery of hemispatial neglect $\mathrm{Neu}$ rology 78, 24-30.

Koelsch, S. (2009). A neuroscientific perspective on music therapy. Ann. N. Y. Acad. Sci. 1169, 406-416.

Koelsch, S., Kasper, E., Sammler, K., Schutze, T., Gunder, T., and Friederici, A. D. (2004). Music, language and meaning: brain signatures of semantic processing. Nat. Neurosci. 7, 302-307.

Komitova, M., Mattsson, B., Johansson, B. B., and Eriksson, P. S. (2005) Enriched environment increases neural stem/progenitor cell proliferation and neurogenesis in the subventricular zone of stroke-lesioned adult rats. Stroke 36, 1278-1282.

Kramer, A. F., and Erickson, K. I. (2007). Capitalizing on cortical plasticity: influence of physical activity on cognition and brain function. Trends Cogn. Sci. (Regul. Ed.) 11, 342-348.

Kwakkel, G., Kollen, B.,and Twisk, J. (2006). Impact of time on improvement of outcome after stroke. Stroke $37,2348-2353$.

Lee, J., Fowler, R., Rodney, D., Cherney, L., and Small, S. L. (2010) IMITATE. An intensive computerbased treatment for aphasia based on action observation and imitation. Aphasiology 244, 449-465.

Lewis, G. N., and Perreault, E. J. (2007). Side of lesion influences interhemispheric inhibition in subjects with post-stroke hemiparesis. Clin. Neurophysiol. 118, 2656-2663.

Lindenberger, U., Nagel, I. E., Chicherio, C., Li, S.-C., Heekeren, H. R., and Bäckman, L. (2008). Age-related decline in brain resources modulates genetic effects on cognitive functioning. Front. Neurosci. 2:2. doi:10.3389/neuro.01.039.2008

Lotze, M., and Cohen, L. G. (2006). Volition and imagery in neurorehabilitation. Cogn. Behav. Neurol. 19, 135-140.

Malykhin, N., Vahidy, S., Michielse, S. Coupland, N., Camicioli, R., Seres, P., and Carter, R. (2011). Structural organization of the prefrontal white matter pathways in the adult and aging brain measured by diffusion tensor imaging. Brain Struct. Funct. $216,417-431$.

Mattsson, B., Sørensen, J. C., Zimmer, Z., and Johansson, B. B. (1997). Neural grafting to experimental cortical infarcts improves behavioral outcome and reduces thalamic atrophy in rats housed in an enriched but not in standard environments. Stroke 28, 1225-1232.
McHughen, S. A., Rodrigues, P. F., Kleim, J. A., Kleim, E. D. Marchal-Crespo, L., Procaccio, V. and Cramer, S. C. (2010). BDNF Val66Met polymorphism influences motor system function in the human brain. Cereb. Cortex 20, 1254-1262.

Michielsen, M. E., Selles, R. W., van der Geest, J. N., Eckhardt, M., Yavuzer G., Stam, H. J., Smits, M., Ribbers, G. M., and Bussmann, J. B. (2011). Motor recovery and cortical reorganization after mirror therapy in chronic stroke patients: a phase II randomized controlled trial. Neurorehabil. Neural Repair 25 223-233.

Mirelman, A., Bonato, P., and Deutsch, J. E. (2008). Effects of training with a robot-virtual reality system compared with a robot alone on the gait of individuals after stroke. Stroke 40 169-174.

Miyajima, F., Oller, W., Mayes, A., Jackson, A., Thacker, N., Rabbitt, P., Pendleton, N., Horan, M., and Payton, A. (2008). Brain-derived neurotrophic factor polymorphism Val66Met influences cognitive abilities in the elderly. Genes Brain Behav. 7, 411-417.

Molenberghs, S., Hayward, L., Mattingly, J. B., and Cunnington, R (2012a). Activation patterns during action observation are modulated by context in mirror system areas. Neuroimage 59, 608-615.

Molenberghs, S., Cunnington, R., and Mattingly, J. B. (2012b). Brain regions with mirror properties: a meta-analysis of 125 human fMRI studies. Neurosci. Biobehav. Rev. 36 , 341-349.

Musacchia, G., Arum, L., Nicol, T., Garstecki, D., and Kraus, N. (2009). Audiovisual deficits in older adults with hearing loss: biological evidence. Ear Hear. 30, 505-514.

Musacchia, G., Sams, M., Skoe, E., and Kraus, N. M. (2007). Musicians have enhanced subcortical auditory and audiovisual processing of speech and music. Proc. Natl. Acad. Sci. U.S.A 104, 15894-15898.

Nishitani, N., and Hari, R. (2000). Temporal dynamics of cortical representation for action. Proc. Natl. Acad. Sci. U.S.A. 97, 913-918.

Nishitani, N., Schürmann, M., Amunts, K., and Hari, R. (2005). Broca's region: from action to language. Physiology 20, 60-69

Noesselt, T., Tyll, S., Boehler, C. N., Budinger, E., Heinze, H.-J., and Driver, J. (2010). Sound-induced enhancement of low-intensity vision: multisensory influences on human sensory-specific cortices and thalamic bodies relate perceptual enhancement of visual detection sensitivity. J. Neurosci. 30 , 12609-13623.

Norton, A., Zipse, L., Marchina, S., and Schlaug, G. (2009). Melodic intonation therapy: shared insights on how it is done and why it might help. Ann. N. Y. Acad. Sci. 1169, 431-436.

Nyberg, L., Eriksson, J., Larsson, A., and Marklund, P. (2006). Learning by doing versus learning by thinking: an MRI study of motor and menal training. Neuropsychologia 44 711-717.

Olsson, C.-J., Jonsson, B., and Nyberg, L. (2008). Learning by doing and learning by thinking: an fMRI study of combining motor and mental training. Front. Hum. Neurosci. 2:5. doi:10.3389/neuro.09.005.2008

Ortique, S., Sinigaglia, C., Rizzolatti, G., and Grafton, S. G. (2010). Understanding action of others: the electrodynamics of the left and right hemispheres. A high-density EEG neuroimaging study. PLoS ONE 5, e12160. doi:10.1371/journal.pone. 0012160

Ozdemis, E., Norton, A., and Schlaug, G. (2006). Shared and distinct neural correlates of singing and speaking. Neuroimage 628-635.

Page, S. J., and Harnich, S. (2012) Thinking about better speech: mental practice for stroke-induced motor speech impairments. Aphasiology 26, 127-142.

Page, S. J., Levine, P., Sisto, S., and Johnston, M. V. (2001a). A randomized efficacy and feasibility study of imagery in acute stroke. Clin. Rehabil. 15, 233-240.

Page, S. J., Levine, P., Sisto, S. A., and Johnston, M. V. (2001b). Mental practice combined with physical practice for upper-limb motor deficit in subacute stroke. Phys. Ther. 81, 1455-1462.

Page, S. J., Murray, C., Hermann, V., and Levine, P. (2011). Retention of motor changes in chronic stroke survivors who were administered mental practice. Arch. Phys. Med. Rehabil. $92,1741-1745$

Page, S. J., Szaflarski, J. P., Eliassen, J. C., Pan, H., and Cramer, S. C. (2009). Cortical plasticity following motor skill learning during mental practice in stroke. Neurorehabil. Neural Repair 23, 382-388.

Parbery-Clark, A., Skoe, E., and Kraus, N. (2009). Musical experience limits the degradative effects of background noise on neural 
processing of sound, J. Neurosci. 29, 14100-14107.

Pascual-Leone, A., Amedi, A., Fregni, F., and Merabet, L. B. (2005). The plastic human brain cortex. Annu. Rev. Neurosci. 28, 377-401.

Patel, A. D. (2003). Language, music, syntax and the brain. Nat. Neurosci. 6, 674-681.

Patel, A. D. (2008). Music, Language, and The Brain. New York: Oxford University Press.

Patel, A. D., and Iversen, J. R. (2007). The linguistic benefits of musical abilities. Trends Cogn. Sci. (Regul. Ed.) 11, 369-372.

Persson, J., Nyberg, L., Lind, J., Larsson, A., Nilsson, L.-G., Ingvar, M., and Buchner, R. I. (2006). Structurefunction correlates of cognitive decline in aging. Cereb. Cortex 16, 907-915.

Press, C., Weiskopf, N., and Kliner, J. M. (2012). Dissociable roles of human inferior frontal gyrus during action execution and observation. Neuroimage 60, 1671-1677.

Przybyla, A., Good, D. C., and Sainsburg, R. L. (2012). Dynamic dominance varies with handedness: reduced interlimb asymmetries in left-handers. Exp. Brain Res. 216, 419-431.

Przybyla, A., Haaland, K. Y., Bagesteiro, L. B., and Sainsburg, R. L. (2011). Motor asymmetry reduction in older adults. Neurosci. Lett. 489, 99-104.

Racette, A., Bard, C., and Peretz, I. (2006). Making non-fluent aphasics speak: sing along! Brain 129, 1571-1584.

Rand, D., Katz, N., and Weiss, P. L. (2009). Intervention using the VMall for improving motor and functional activity of the upper extremity in post stroke participants. Eur. J. Phys. Rehabil. Med. 45, 113-121.

Raymer, A. M., Singletary, F., Rodriguez, A., Ciampitti, M., Heilman, K. M., and Rothi, L. J. (2006). Effect of gesture + verbal treatment for noun and word retrieval in aphasia. J. Int. Neuropsychol. Soc. 12, 867-882.

Rengachary, J., He, B. J., Shulman, G. L., and Corbetta, M. (2011). A behavioral analysis of spatial neglect and its recovery after stroke. Front. Hum. Neurosci. 5:29. doi:10.3389/fnhum.2011.00029

Rinehart, J. K., Singleton, R. E., Adair, J. C., Sadek, J. R., and Haaland, K. Y. (2008). Arm use after left or right hemiparesis is influenced by hand preference. Stroke 28, 1667-1673.

Rizzolatti, G., and Arbid, M. A. (1998). Language within our grasp. Trends Neurosci. 21, 188-194.
Rizzolatti, G., and Craighero, L. (2004). The mirror-neuron system. Annu. Rev. Neurosci. 27, 169-192.

Sainburg, R. L., and Duff, S. V. (2006). Does motor lateralization have implications for stroke rehabilitation? J. Rehabil. Res. Dev. 43, 311-322.

Saposnik, G., Levin, M., and for the Stroke Outcome Research Canada (SORCan) Working Group. (2011). Virtual reality in stroke rehabilitation. a meta-analysis and implications for clinicians. Stroke 42, 1380-1386

Särkämö, T., Tervaniemi, M., Laitinen, S., Forsblom, A., Soinila, S., Mikkonen, M., Autti, T., Silvennoinen, H. M., Erkkilä, J., Laine, M., Peretz, J., and Hietanen, M. (2008). Music listening enhances cognitive recovery and mood after middle cerebral artery stroke. Brain 131, 866-876.

Sathian, K., Greenspan, A., and Wolf, S. L. (2000). Doing it with mirrors: a case study of a novel approach to neurorehabilitation. Neurorehabil. Neural Repair 14, 73-76.

Schaefer, S. Y., Haaland, K. Y., and Sainburg, R. L. (2009). Dissociation of initial trajectory and final position errors during visuomotor adaptation following unilateral stroke. Brain Res. 1298, 78-91.

Schaefer, S. Y., Haaland, K. Y., and Sainsburg, R. L. (2007). Ipsilateral motor deficits following stroke reflect hemispheric specializations for movement control. Brain 130, 2146-2158.

Schaefer, S. Y., Mutha, P. K., Haaland, K. Y., and Sainburg, R. L. (2011). Hemispheric specialization for movement control produces dissociable differences in online corrections after stroke. Cereb. Cortex [Epub ahead of print].

Schauer, M., and Mauritz, K. M. (2003). Musical motor feedback (MMF) in walking hemiparetic stroke patients: randomized trials of gate improvement. Clin. Rehabil. 17, 713-722.

Schlaug, G., Marchina, S., and Norton, A. (2009). Evidence for plasticity in white-matter tracts of patients with chronic Broca's aphasia undergoing intense intonation-based speech therapy. Ann. N. Y. Acad. Sci. 1169, 385-394.

Schlaug, G., Marchina, S., and Wan, C. Y. (2011). The use of noninvasive brain stimulation techniques to facilitate recovery from post-stroke aphasia. Neuropsychol. Rev. 21, 288-301.
Shahin, A. J. (2011). Neurophysiological influence of musical training on speech perception. Front. Psychol. 2:126. doi:10.3389/fpsyg.2011.00126

Shams, L., and Seitz, A. R. (2008). Benefits of multisensory learning. Trends Cogn. Sci. (Regul. Ed.) 12, 411-416.

Skipper, J. I., Goldin-Meadow, S. Nusbaum, H. C., and Small, S. L. (2007a). Speech associated gestures, Broca's area, and the human mirror system. Brain Lang. 101, 260-277.

Skipper, J. I., van Wassenhove, V., Nusbaum, H. C., and Small, S. L. (2007b). Hearing lips and seeing voices: how cortical areas supporting speech production mediate audiovisual speech perception. Cereb. Cortex 17, 2387-2399.

Skipper, J. I., Goldin-Meadow, S., Nusbaum, H. C., and Small, S. L. (2009). Gestures orchestrate brain networks for language understanding. Curr. Biol. 19, 661-667.

Song, J. H., Skoe, E., Banai, K., and Kraus, N. (2011). Training to improve hearing speech in noise: biological mechanism. Cereb. Cortex. [Epub ahead of print].

Soto, D., Funes, M. J., Guzmán-Garcia, A., Warbrick, T., Rotshtein, P., and Humphrey, G. W. (2009). Pleasant music overcomes the loss of awareness in patients with visual neglect. Proc. Natl. Acad. Sci. U.S.A. 106, 6011-6016.

Sparing, R., Thimm, M., Hesse, M. D., Küst, J., Karbe, H., and Fink, G. R. (2009). Bidirectional alterations of interhemispheric parietal balance by non-invasive cortical stimulation. Brain 132, 3011-3020.

Sporns, O. (2011). Networks of the Brain Cambridge, MA: The MIT Press.

Sporns, O., Chialvo, D. R., Kaiser, M. and Hilgetag, C.-C. (2004). Organization, development and function of complex brain networks. Trends Cogn. Sci. (Regul. Ed.) 8, 418-425.

Sporns, O., Honey, C. J., and Kötter, R. (2007). Identification and classification of hubs in brain networks. PLoS ONE 10, e1049. doi:10.1371/journl.pone.0001049

Strait, D. L., and Kraus, N. (2011). Can you hear me now? musical training shapes functional brain networks for selective auditory attention and hearing speech in noise. Front. Psychol. 2:113, 1-10.

Straube, T., Schultz, A., Geipel, K., Mentzel, H.-J., and Miltner, W. H. R. (2008). Dissociation between singing and speaking in expressive aphasia: the role of song familiarity. Neuropsychologia 46, 1505-1512.

Stroke Unit Trialists' Collaboration. (2007). Organized inpatients stroke unit care for stroke. Cochrane Database Syst. Rev. 2007, CD000197.

Takahashi, C. D., Der-Yeghiaian, L., Le, V., Motiwala, R. R., and Cramer, S. C. (2008). Robot-based therapy after stroke. Brain 131, 425-437.

Tessari, A., Canessa, N., Ukmar, M., and Rumiati, R. I. (2007) Neuropsychological evidence for a strategic control of multiple routes in imitation. Brain 130, 1111-1126.

Thaut, M. H., Gardner, J. C., Holmberg, D., Horwitz, J., Kent, L., Andrews, G., Donelan, B., and McIntosh, G. R. (2009). Neurologic music therapy improves executive function and emotional adjustment in traumatic brain injury rehabilitation. Ann. N. Y. Acad. Sci. 131, 866-876.

Thaut, M. H., Leins, A. K., Rice, R. R., Argstatter, H., Kenyon, G. P., McIntosh, G. C., Bolay, H. V., and Fetter, M. (2007). Bobath training in near-ambulatory patients early poststroke: a single-blind, randomized trial. Neurorehabil. Neural Repair 21, 455-459.

Tsirlin, I., Dupierrix, E., Chokron, S. Coquillart, S., and Ohlmann, T. (2009). Uses of virtual reality for diagnosis, rehabilitation and study of unilateral spatial neglect: review and analysis. Cyberpsychol. Behav. 12, 175-181.

Urbanski, M., Thiebaut de Schotten, M., Rodrigo, S., Oppeheim, C. Touzé, E., Méder, J.-F., Moreau, K., Loeper-Jeny, C., Dubois, B., and Bartolomeo, P. (2011). DTIMR tractography of white matter damage in stroke patients with neglect. Exp. Brain Res. 208, 491-505.

Vines, B. W., Norton, A. C., and Schlaug, G. (2011). Non-invasive brain stimulation enhances the effects of melodic intonation therapy. Front. Psychol. 2:230. doi:10.3389/fpsyg.2011.00230

Wang, J., and Sainburg, R. L. (2007). The dominant and non-dominant arms are specialized for stabilizing different features of task performance. Exp. Brain Res. 178, 565-570.

Wang, L., Yu, C., Chen, H., Qin, W., He, Y., Fan, F., Zhang, Y., Wang, M., Li, K., Zang, Y., Woodwaard, T. S., and 
Zhu, C. (2010). Dynamic functional reorganization of the motor execution network after stroke. Brain 133, 1224-1238.

Westlake, K. P., and Nagarajan, S. S. (2011). Functional connectivity in relation to motor performance and recovery after stroke. Front. Syst. Neurosci. 5:8. doi:10.3389/fnsys.2011.00008

Wong, P. C., Skoe, E., Russo, N. M., Dees, T., and Kraus, N. (2007). Musical experience shapes human brainstem encoding of linguistic pitch patterns. Nat. Neurosci. 10, 420-422.

$\mathrm{Xu}$, J., Gannon, P. J., Emmorey, K., Smith, J. F., and Braun, A. R. (2009). Symbolic gestures and spoken language are processed by a common neural system. Proc. Natl. Acad. Sci. U.S.A. 106, 20664-20669.

Yavuzer, G., Selles, P., Sezer, N., Sütbeyaz, S., Bussmann, J. B., Köseoglu, F., Atay, M. B., and Stam, H. J. (2008). Mirror therapy improves hand function in subacute stroke: a randomized controlled trial. Arch. Phys. Med. Rehabil. 89, 393-398.

You, D. S., Kim, D. Y., Chun, M. H., Jung, S. E., and Park, S. J. (2011). Cathodal transcranial direct current stimulation of the right Wernicke's area improves comprehension in subacute stroke patients. Brain Lang. 119, 1-5.

Zamora-López, G., Zhou, C., and Kurths, J. (2011). Exploring brain function from anatomical connectivity. Front. Neurosci. 5:83. doi:10.3389/fnins.2011.00083

Zamora-López, G., Zhou, C., Musacchia, G., Arum, L., Nicol, T., Garstecki, D., and Kraus, N. (2009). Audiovisual deficits in older adults with hearing loss; biological evidence. Ear Hear. 30, 505-514.

Zatorre, R. J., Chen, J. L., and Penhune, V. A. (2007). When the brain plays music: auditory-motor interactions in music perception and production. Nat. Rev. Neurosci. 8, 547-558.

Conflict of Interest Statement: The author declares that the research was conducted in the absence of any commercial or financial relationships that could be construed as a potential conflict of interest.

Received: 21 November 2011; accepted: 08 March 2012; published online: 09 Apri 2012.

Citation: Johansson BB (2012) Multisensory stimulation in stroke rehabilitation. Front. Hum. Neurosci. 6:60. doi: 10.3389/fnhum.2012.00060

Copyright (c) 2012 Johansson. This is an open-access article distributed under the terms of the Creative Commons Attribution Non Commercial License, which permits non-commercial use, distribution, and reproduction in other forums, provided the original authors and source are credited. 